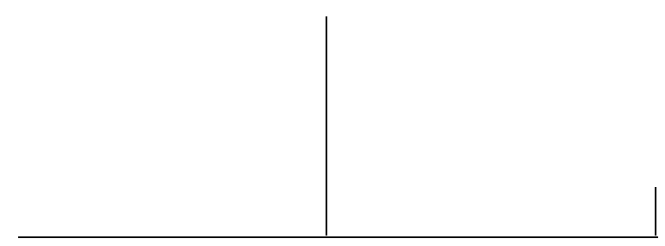

Rev. Latinoam. Psicopat. Fund., São Paulo, v. 14, n. 4, p. 595-598, dezembro 2011

\title{
Editorial
}

\section{Travessia em análise: dois eus e um saquinho de culpas}

\author{
Ana Cleide Guedes Moreira
}

Um dia escutei uma réplica vinda do divã, em forma de grunhido, quase imperceptível, mas amuado. A analisanda protestava. Pensei que havia sido excessiva em algo, mas o quê? Acabava de me alongar um pouquinho mais em uma fala sobre a melancolia. Escorregão racional, tentativa didática, invasão do campo analítico por excesso de representações do analista? Metapsicologia é que não foi, pois produziu resistência.

A tentativa frustrada de interpretação, ao contrário de permitir atravessar um recalque, rendeu barricadas de obstrução. Não havia dúvidas, havia sido interditado um caminho. Silenciei. A sessão continuou. No processo analítico haveria novas oportunidades de retomar o sentido desse protesto em forma de resmungo, após o anúncio de um eu, outro que não o da própria analisanda.

Ela, como intelectual da revolução socialista, solicitava uma análise em que o clínico não fosse senão a porta de entrada para movimentos psíquicos em ampla escala, cidadã do mundo para o qual fora criada por uma família de imigrantes italianos. Sua formação subjetiva exigia do clínico mais do que a transmissão, pelo divã, de uma prática já teorizada, requeria pensamento. Mas não apenas lógica formal, insuficiente para dar conta do mal-estar na cultura em globalização. Este caso exige pesquisa ainda em andamento, num campo onde a lógica dialética é partícipe do processo analítico, mas também insuficiente, pois os pensamentos inconscientes não se deixam aprisionar em sínteses, antes 


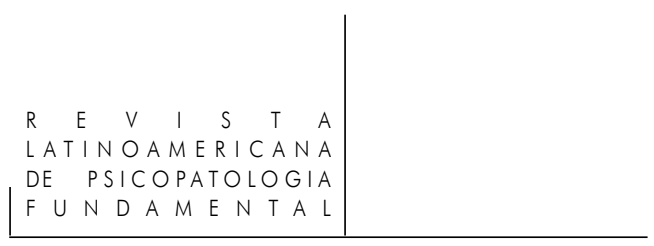

manifestando-se como complexos. E inclui ainda a busca permanente de uma sólida bildung de sua analista.

Em "Psicologia das massas e análise do ego" (1921), Freud postula que cada indivíduo cai sob a influência de uma única pessoa de cada vez - raramente mais de uma, ou duas. Cair sobre influência de um outro, eis o que ele vai examinar neste texto paradigmático.

Ao analisar a hipnose e a sugestão frente aos avanços alcançados na metapsicologia com relação aos conceitos de identificação, narcisismo, ideais de eu, Freud sustenta que toda psicologia é, desde o início, Psicologia social.

"Cair sobre influência de uma única pessoa" ele aprendeu, desde o método hipnótico, depois hipnótico-catártico, antes que chegasse à associação livre e atenção flutuante, que este método lhe oferecia um lugar privilegiado para a observação clínica do fenômeno da transferência, que se dá entre o eu e o outro.

A análise do eu, que havia proporcionado tanta compreensão metapsicológica e psicopatológica do desenvolvimento do humano, agora era dedicada a analisar um fenômeno social, a saber, as instituições. Neste texto duas, a Igreja e o Exército.

Freud forneceu as bases para uma analítica da família burguesa nascente e, para a derrocada das famílias da realeza, em vários pontos da Europa, especialmente a partir da análise dos nobres russos e franceses que procuravam a Bergasse 19, no centro do Império Austro-Húngaro. Esta instituição era alvo de pesquisas nas ciências sociais e no materialismo histórico, e Reich também colaborou com a transformação da família na Revolução Russa. Passada a I Grande Guerra, Freud parecia ter reunido novo fôlego junto aos que com ele restaram na segunda década do século XX. Vários psicanalistas estiveram no front - onde também lutaram dois filhos de Fredu - e ele teve como dedicar-se à análise do Exército, onde a concepção de estrutura libidinal juntou a relação entre o líder e as massas pelo conceito de identificação, e as análises de neuroses traumáticas de guerra forneceram a dúvida preciosa sobre a tese fundamental do sonho como realização de desejo. Uma nova tópica estava sendo gestada, assim como uma nova concepção de dualidade pulsional, ao mesmo tempo em que o mundo que o circundava encontrava-se grávido do ovo da serpente, o nazismo e seus semelhantes, o fascismo e as ditaduras de esquerda. Totalitarismos do século XX.

Nesse contexto a família era analisada em sua complexidade edípica permitindo a Freud abrir esse magnífico texto apontando as quatro posições que o outro pode ocupar na transferência: modelo, como o pai para o menino, objeto como a mãe para meninas e meninos, auxiliar como os irmãos entre si, que também podem ocupar o lugar de adversário, como o pai.

A configuração da transferência postulada em Psicologia das massas e análise do eu, merece uma revisão sistemática da literatura, e exige do clínico a ob- 
servação de suas vicissitudes pulsionais, ancorada no conceito de transferência e das novas formulações sobre a posição clínica na pólis, frente aos avanços da acumulação capitalista sobre a saúde mental e a proliferação de novas moléculas atuantes como psicotrópicos.

Minha analisanda, ao longo dos últimos dez anos, em sua aventura analítica, me fez percorrer, reservadamente implicada, várias dessas posições, enquanto enfrentava em sua vida diferentes posições na pólis, frente aos diferentes arranjos sociais reformistas e revolucionários da história recente do século XX.

A análise do eu e do lugar do líder na estrutura libidinal de formações sociais e do Estado, muitas vezes foram convocadas ao divã nesse período que derivou do fim da URSS, da queda do muro de Berlim, da ascensão do neoliberalismo e da globalização.

As perdas ligadas aos ideais de eu foram interrogadas nesta análise, sucessivas vezes, e os processos melancólicos foram enfrentados com dor e sofrimento psíquico, mas com os benefícios da travessia por abismos em busca das razões que o eu buscava clarificar, para as delicadezas de sua ruína e da sombra que o cobria.

Vulnerável aos processos sociohistóricos de seu tempo, a analisanda claudicou numerosas vezes entre ocupar o espaço público com seu ideal de igualdade mais a concepção marxista de luta de classes, com que sabia lidar muito bem, e as novas possibilidades de luta política colocadas pelo retorno à democracia. Com objetivos definidos por suas convicções "mais intuitivas que teóricas" - jamais deixou de repetir, ocupou o espaço democrático com desenvoltura, em mediação entre as massas e as elites políticas, de modo a alcançar produzir formas de resistência social ao avanço do capitalismo selvagem sobre a Amazônia brasileira, que o final da ditadura militar deixou como legado aos que a ela sobreviveram e às novas gerações.

Em seu processo analítico descobriu que carregava um "saquinho de culpas", atrelado como canga às suas costas, por um carrasco imaginário que a dividia em duas: uma que seguia vivendo com seus ideais e, outra, que se fazia ouvir permanentemente, acusadora, crítica, exigente, deixando-a, por vezes, exausta no cotidiano assoberbado de trabalho e luta.

Em seu resmungo, entendeu a analista um protesto pela forma desajeitada como esta se colocou no campo transferencial, ocupando o lugar de irmã, de auxiliar que, ainda que lhe fosse disposto, jamais deveria ocupar, como de resto qualquer outro, permanentemente. A sua travessia por processos melancólicos ficou povoada demais, de repente. "Nós, melancólicos ..." foi como a analista iniciara uma tentativa de formular uma hipótese interpretativa para o que escutava naquele preciso instante, mas colocar-se no lugar imaginário de auxiliar na desventura socialista, foi um modo de resistir àquela análise, sinal de vulnerabilidade do lado da poltrona. 


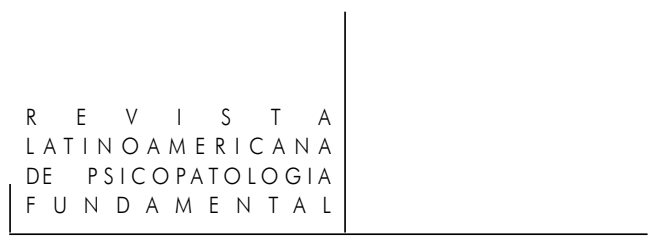

Clinicamente a hipótese para a direção do tratamento sustentava que ela precisaria fazer o luto de ideais perdidos, o que incluía reconhecer que o século XX terminara com a derrocada dos socialismos, de onde o neoliberalismo grassa triunfante, em sua perversão da libido das massas desejosas de igualdade, demonstrada por sua luta, pelo menos, desde o século XVII. Como erva daninha a corroer a cripta melancólica, era preciso acreditar que a travessia pelo luto permitiria emergir em uma depressividade, condição para a saída da analisanda da compulsão a repetir o recalque de seu desejo, em prol do investimento no desejo e nos ideais coletivos.

Como afirmou Marthe Robert (apud Wieder, 2010), a grande crítica literária, a obra de Freud é o Discurso do método de nossos tempos. Urge desenvolver pesquisa que leve em conta a subjetividade e o inconsciente, pois a razão não está só, e o eu não é o senhor, nem em sua própria casa.

\section{Referências}

Freud, S. (1921). Psicologia de grupo e análise do ego. In: Edição Standard Brasileira das Obras Psicológicas Completas de Sigmund Freud. Rio de Janeiro: Imago, 1996.

Wieder, T. L'Explorateur de l'ame. Le Monde. Hors-Série Freud, Paris, 2010.

\section{Ana Cleide Guedes Moreira}

Psicóloga; Mestre e Doutora em Psicologia Clínica pela Pontifícia Universidade Católica de São Paulo - PUC-SP (São Paulo, SP, Br); Professora do Programa de Pós-Graduação Mestrado em Psicologia, Pesquisadora do Hospital Universitário João de Barros Barreto (Belém, PA, Br); Diretora do Laboratório de Psicanálise e Psicopatologia Fundamental da Universidade Federal do Pará (Belém, PA, Br); Pesquisadora da Associação Universitária de Pesquisa em Psicopatologia Fundamental (São Paulo, SP, Br); Pesquisadora do Grupo de Estudos e Pesquisas Eneida de Moraes sobre Mulher e Relações de Gênero - GEPEM (Belém, PA, $\mathrm{Br}$ ); Pesquisadora-Visitante do Laboratório Interdisciplinar de Pesquisa e Intervenção Social da Pontifícia Universidade Católica do Rio de Janeiro - PUC-Rio (Rio de Janeiro, RJ, Br); Pesquisadora do GT ANPEPP Dispositivos Clínicos em Saúde Mental; PesquisadoraVisitante do Laboratório de Psicopatologia Fundamental da Pontifícia Universidade Católica de São Paulo - PUC-SP (São Paulo, SP, Br); Chercheur associé à l' Université Paris 7 Denis-Diderot (Paris, França); Membro da Réseau Internacional de Psychopathologie Transculturelle (Paris, França).

Travessa Tupinambás 540-1301 - Batista Campos

66033-815 Belém, PA, Brasil

Fone: 55 91- 32725794 / Celular: 55 91- 81177158

e-mail: acleide@uol.com.br 